\title{
Biochemical mechanism underlying hypertriglyceridemia and hepatic steatosis/ hepatomegaly induced by acute schisandrin B treatment in mice
}

Yi Zhang ${ }^{1+}$, Jing Zhao ${ }^{2 \dagger}$, Shu-Feng Zhou ${ }^{3}$, Zhi-Ling Yu ${ }^{4}$, Xiao-Yan Wang ${ }^{1}$, Pei-Li Zhu', Zhu-Sheng Chu', Si-Yuan Pan ${ }^{1,2^{*}}$, Ming $\mathrm{Xie}^{5^{*}}$ and Kam-Ming Ko ${ }^{6}$

\begin{abstract}
Background: It has been demonstrated that acute oral administration of schisandrin B (Sch B), an active dibenzocyclooctadiene isolated from Schisandrae Fructus (a commonly used traditional Chinese herb), increased serum and hepatic triglyceride (TG) levels and hepatic mass in mice. The present study aimed to investigate the biochemical mechanism underlying the Sch B-induced hypertriglyceridemia, hepatic steatosis and hepatomegaly.

Methods: Male ICR mice were given a single oral dose of Sch B $(0.25-2 \mathrm{~g} / \mathrm{kg})$. Sch B-induced changes in serum levels of biomarkers, such as TG, total cholesterol (TC), apolipoprotein B48 (ApoB 48), very-low-density lipoprotein (VLDL), non-esterified fatty acid (NEFA) and hepatic growth factor (HGF), as well as hepatic lipids and mass, epididymal adipose tissue (EAT) and adipocyte size, and histological changes of the liver and EAT were examined over a period of 12-120 h after Sch B treatment.

Results: Serum and hepatic TG levels were increased by 1.0-4.3 fold and 40-158\% at 12-72 h and 12-96 h, respectively, after Sch B administration. Sch B treatment elevated serum ApoB 48 level (up to 12\%), a marker of exogenous TG, but not VLDL, as compared with the vehicle treatment. Treatment with Sch B caused a time-/dose-dependent reduction in EAT index (up to 39\%) and adipocyte size (up to 67\%) and elevation in serum NEFA level (up to 55\%). Sch B treatment induced hepatic steatosis in a time-/dose-dependent manner, as indicated by increases in total vacuole area (up to 3.2 fold vs. the vehicle control) and lipid positive staining area (up to $17.5 \times 10^{3} \mu^{2}$ ) in liver tissue. Hepatic index and serum HGF levels were increased by $18-60 \%$ and $42-71 \%$ at $12-120 \mathrm{~h}$ and $24-72 \mathrm{~h}$ post-Sch B dosing, respectively. In addition, ultrastructural changes, such as increase in size and disruption of cristae, in hepatic mitochondria were observed in Sch B-treated mice.

Conclusion: Our findings suggest that exogenous sources of TG and the breakdown of fat storage in the body contribute to Sch B-induced hypertriglyceridemia and hepatic steatosis in mice. Hepatomegaly (a probable hepatotoxic action) caused by Sch B may result from the fat accumulation and mitochondrial damage in liver tissue.
\end{abstract}

Keywords: Schisandrin B, Hypertriglyceridemia, Lipolysis, Chylomicron, Hepatomegaly, Hepatic steatosis

\footnotetext{
*Correspondence: siyuan-pan@163.com; xieming603@126.com

${ }^{\dagger}$ Equal contributors

'Department of Pharmacology, Beijing University of Chinese Medicine,

Beijing 100102, China

${ }^{5}$ Department of Formulaology, Beijing University of Chinese Medicine, Beijing

100029, China

Full list of author information is available at the end of the article
}

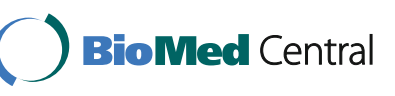

(c) The Author(s). 2017 Open Access This article is distributed under the terms of the Creative Commons Attribution 4.0 International License (http://creativecommons.org/licenses/by/4.0/), which permits unrestricted use, distribution, and reproduction in any medium, provided you give appropriate credit to the original author(s) and the source, provide a link to the Creative Commons license, and indicate if changes were made. The Creative Commons Public Domain Dedication waiver (http://creativecommons.org/publicdomain/zero/1.0/) applies to the data made available in this article, unless otherwise stated. 


\section{Background}

Primary or secondary hyperlipidemia featuring raised serum triglycerides (TG) either alone or combined with elevated serum low density lipoprotein (LDL)-cholesterol or low serum LDL-cholesterol concentrations has a high prevalence in developing and developed countries [1]. It is commonly associated with a set of metabolic abnormalities, such as central obesity, type 2 diabetes, and coronary heart disease [2-4]. In addition, patients with severe hypertriglyceridemia also have increased incidences in certain diseases such acute pancreatitis [5], chronic periodontitis [6] and schizophrenia [7]. Furthermore, high blood level of TG may cause nonalcoholic fatty liver disease (NAFLD), a common chronic liver disorder which is causally related to the development of hepatic steatosis and cirrhosis [8] as well as the increased cardiovascular risk (CVR) [9]. In view of adverse health consequences associated with hypertriglyceridemia secondary to hepatic steatosis, the search for lipid-lowering drugs has been an area of intensive research. In this connection, the pathophysiology of hypertriglyceridemia is complex, involving the overproduction of hepatic very low density lipoprotein (VLDL) and intestinal chylomicron (CM), dysfunctional peripheral lipolysis, and impaired clearance of TGenriched remnant lipoproteins [10]. The biochemical mechanism underlying hypertriglyceridemia in relation to other organs/tissues remains relatively unclear. The understanding of pathophysiological processes that lead to the metabolic disturbances associated with hypertriglyceridemia can open up avenues for the development of lipid-lowering drugs which act on novel targets.

Schisandrin B (Sch B) is the most abundant active lignoid component in Schisandrae Fructus, a commonly used herb in Chinese medicine. Pharmacological studies on schisandrin B have revealed a wide spectrum of biological activities particularly those related to liver functions (including lipid metabolism). Up to know, Sch B has been shown to produce anti-inflammatory $[11,12]$, cardioprotective $[13,14]$, hepatoprotective $[15,16]$, and anticancer actions $[17,18]$ in vivo and in vitro. However, the use of Schisandrae Fructus and its active components is more popular in China and other Asian countries which are strongly influenced by the practice of Chinese medicine. Previous studies from our laboratory have demonstrated that Sch B treatment increased serum and hepatic TG levels, serum alanine aminotransferase (ALT) activity and hepatic mass in mice, suggestive of a mouse model of hypertriglyceridemia combined with hepatic steatosis and injury [19-21]. It is well known that TG in bloodstream is derived from exogenous (dietary sources) and endogenous (synthesis in liver using fatty acids) pathways. However, the biochemical processes involved in the Sch B-induced changes in TG metabolism remains unclear. In the present study, we endeavored to elucidate the biochemical mechanism involved in Sch B-induced hypertriglyceridemia and hepatomegaly.

\section{Methods \\ Chemicals and reagents}

Sch B was purified from the petroleum ether extract of dried SF by silica gel column chromatography as previously described [22]. The purity of Sch B, as determined by high performance liquid chromatography analysis, was higher than 95\%. Betis extra virgin olive oil was purchased from a local market. Assay kit for TG (certificate number 135991) and total cholesterol (TC) (certificate number 135991) were purchased from Zhongsheng Beikong Biotechnology Science Inc. (Beijing, People's Republic of China). Assay kits for serum apolipoprotein B48 (Apo B48, certificate number F20030794), very-lowdensity lipoprotein (VLDL, certificate number E11030776) and hepatocyte growth factor (HGF, certificate number H03030777) were bought from Cusabio Biotech (Wuhan, China). Assay kit for non-esterified fatty acid (NEFA, certificate number 20150130.40030) was purchased from Rigor Bioscience Development LTD (Beijing, China).

\section{Animal treatment}

Male Institute of Cancer Research (ICR) mice (Grade II, certificate number 118, SCXK [jing] 2006-0009), weighing 18-20 g, were purchased from the Vital River Laboratory Animal Technology Co., Ltd. (Beijing, People's Republic of China). They were maintained at $20-21{ }^{\circ} \mathrm{C}$, with a relative humidity of $50-55 \%$ and allowed free access to water and food. Animals were housed ten in each cage, and ten mice were assigned to each group. Experiments were performed when the animals had attained a body weight of 25-28 g. All experimental procedures were approved by the University Committee on Research Practice in Beijing University of Chinese Medicine.

\section{Experimental design \\ Design one}

In this study, the time response of Sch B-induced changes in serum TG, TC, NEFA, Apo B48, VLDL, and HGF levels, as well as hepatic steatosis were investigated. In addition, histopathological changes of liver and adipose tissues were also examined. Mice were orally treated with Sch B (1 g/ $/ \mathrm{kg})$ suspended in olive oil. The dose of Sch B was chosen with reference to our previous studies. Control animals were orally administered the vehicle (ie, olive oil $5 \mathrm{~mL} / \mathrm{kg}$ ) only. After $12,24,48,72,96$, and $120 \mathrm{~h}$ post-dosing, mice were sacrificed under light ether anesthesia. Blood samples were collected from the orbital vein, liver and adipose tissue samples were also obtained and subjected to biochemical analysis and histological examination. 


\section{Design two}

This study was designed to investigate the dose response of Sch B-induced changes in parameters described above. Mice were orally administered with Sch B at increasing doses of $0.25,0.5,1$, and $2 \mathrm{~g} / \mathrm{kg}$, suspended in olive oil. Control (ie, non-Sch B-treated) animals were given the vehicle. Mice were sacrificed at 24 or $48 \mathrm{~h}$ after Sch B treatment.

\section{Biochemical analysis}

Serum samples were prepared by centrifuging the whole blood for $8 \mathrm{~min}$ at $2,000 \times g$ and stored at $-70{ }^{\circ} \mathrm{C}$ until used for biochemical analysis. Liver tissue samples were homogenized in 9 volumes of saline using two 10-s bursts of a tissue disintegrator at 13,500 rpm, and the homogenate was then centrifuged at $2,000 \times g$ for $15 \mathrm{~min}$ to obtain the supernatants. Hepatic supernatant $(30 \mu \mathrm{L})$ and serum $(10 \mu \mathrm{L})$ were used to determine TG levels using the GPO-PAP (glycerol-3-phosphate oxidase and phenol + aminophenazone) method. Serum NEFA level was measured by automatic Biochemistry Analyzer (Beckman coulter Synchron CX4 PRO, Brea, CA, USA). Serum Apo B48, VLDL and HGF levels were determined using enzyme-linked immunosorbent assay (ELISA) with polyclonal antibodies according to the manufacturer's instructions.

\section{Hematoxylin and eosin (HE) staining}

A small block of adipose tissue was dissected from the left epididymis, which was fixed in $10 \%$ neutral buffered formalin and then embedded in paraffin. The paraffin block was cut into $5 \mu \mathrm{M}$ thick slices, and they were stained with hematoxylin and eosin, according to the manufacturer's protocol. Representative areas were photographed under the viewing of a Nikon 90i microscope (Nikon, Tokyo, Japan) at a magnification of $20 \times$. The average surface area of 10 adipocytes in each slice section was analyzed with Image-Pro Plus 6.0 software (Media Cybernetics Inc. USA). The same procedures were performed for samples prepared from liver tissues. Five images of hepatic lobules in each liver tissue slice were quantified by an observer that was blinded to the experimental design, and the total area of vacuoles in each slice was also computed by Image-Pro Plus 6.0 software.

\section{Oil Red $O$ staining}

Fresh liver tissue sample was frozen and cut into frozen slices at $6 \mu \mathrm{M}$ thickness. They were stained with a filtered solution of $1 \%$ Oil Red O (Sigma-Aldrich) in 60\% aqueous triethylphosphate for $15 \mathrm{~min}$, followed by rinsing with $60 \%$ isopropanol. The tissue slices were then mounted in glycerin jelly, and five images were randomly selected from each slice at a magnification of $200 \times$ for the estimation of lipid positive staining area, using Image-Pro Plus 6.0 software.

\section{Trasmission electron microscopy (TEM)}

For electron microscopy, the liver biopsy was rapidly cut into small pieces which were transferred to the following fixatives $(\mathrm{pH} 7.4)$ at $4{ }^{\circ} \mathrm{C}$ : a) $2 \%$ glutaraldehyde Sorensen's phosphate buffer for $3 \mathrm{~h}$; b) $1 \% \mathrm{OsO}_{4}$ phosphate buffer for $2 \mathrm{~h}$, followed by washing with same buffer and further incubated for $24-48 \mathrm{~h}$ in a refrigerator $\left(4{ }^{\circ} \mathrm{C}\right)$. Liver tissue sections were dehydrated with absolute ethanol and embedded in Epon 812. Observations were made on $0.5-\mu \mathrm{m}$ thick Epon sections from controls that were stained with toluidine blue. After ultra-thin $(600 \AA)$ sectioning by ultramicrotome, the sections were lightly counter-stained with uranyl acetate and lead citrate and were viewed under JEM-1230 electron microscope for lipid inclusion in the cytoplasm of hepatocytes and the morphology of mitochondria.

\section{Measurement of hepatic/EAT index}

The liver and epididymal adipose tissue (EAT) were excised and weighed. Hepatic or adiposity index was estimated from the ratio of liver or adipose tissue weight to body weight (liver or adipose tissue weight/body weight $\times 100$ ).

\section{Statistical analysis}

All values are expressed as means \pm standard error of the mean. Data were analyzed by one-way analysis of variance (ANOVA) using SPSS (version 16.0) statistical analysis program, and then differences among means were determined using Dunnett's multiple comparisons test or post hoc analysis. Differences were considered significant at $P<0.05$. The parameters of $E_{\max }$ (maximal effect), $K_{\mathrm{D}}$ (affinity), and $\mathrm{p} D_{2}$ (an index of affinity) were obtained using the Scott's plot method.

\section{Results \\ Serum \\ Effects of Sch B treatment on serum TG and TC levels}

Serum TG levels were elevated by $262,427,289$, and $100 \%$ at $12,24,48$ and $72 \mathrm{~h}$ after Sch B $(1 \mathrm{~g} / \mathrm{kg})$ treatment, respectively, when compared with the control group (Fig. 1a). Sch B dose-dependently increased serum TG levels by $147-268 \%$, with values of $E_{\max }(5.19 \mathrm{mmol} / \mathrm{L}), K_{\mathrm{D}}$ $(0.82 \mathrm{mmol} / \mathrm{kg})$ and $\mathrm{p} D_{2}$ (3.09) being estimated (Fig. 1b). Serum TC concentrations in mice receiving Sch B at dose of $1 \mathrm{~g} / \mathrm{kg}$ were markedly increased by $13 \%(P<0.05)$ and $21 \%(P<0.01)$ at 24 and $48 \mathrm{~h}$ post treatment, respectively, but it was decreased by $13 \%(P<0.05)$ at $6 \mathrm{~h}$ post dosing (Fig. 1c). Sch B (0.25-2 g/kg) treatment dosedependently increased serum TC levels (up to $17 \%$ ), with values of $E_{\max }, K_{\mathrm{D}}$, and $\mathrm{p} D_{2}$ being estimated to 

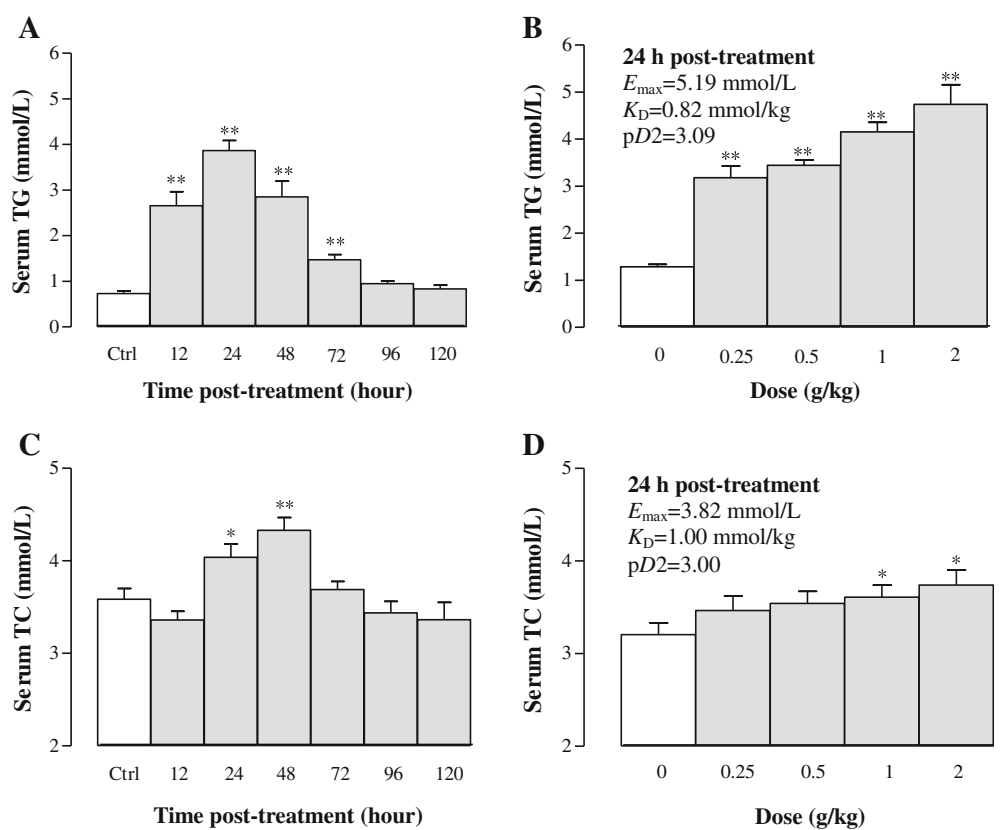

Fig. 1 Time/dose response of schisandrin B (Sch B) treatment on serum triglyceride (TG) and total cholesterol (TC) levels. Mice were orally administered with Sch B (1 g/kg, suspended in olive oil). Control (untreated) animals received the vehicle (5 ml/kg) only. For the time course study, serum TG and TC levels were measured at 12, 24, 48, 72, 96, and $120 \mathrm{~h}$ after Sch B treatment or $24 \mathrm{~h}$ post-vehicle treatment (a and $\mathbf{c}$ ). Preliminary studies indicated that vehicle-treated mice did not show any changes in serum lipids from 12 to $120 \mathrm{~h}$ post treatment. For the dose-response study, serum TG and TC were determined at $24 \mathrm{~h}$ in the Sch B-treated mice. Pharmacodynamic parameters (b and $\mathbf{d}$ ) $E_{\max }$ (maximal effect), $K_{\mathrm{D}}$ (affinity), and $\mathrm{p} D_{2}$ (an index of affinity) were estimated with the Scott's plot method. Values given are the mean \pm SEM, with $n=10 .{ }^{*} P<0.05,{ }^{* *} P<0.01$ vs control, using a one-way ANOVA followed by Dunnett's multiple comparisons test, Student's t-test or post-hoc analysis

be $3.82 \mathrm{mmol} / \mathrm{L}, 1.00 \mathrm{mmol} / \mathrm{kg}$, and 3.00 , respectively, at $24 \mathrm{~h}$ post treatment (Fig. 1d).

\section{Effects of Sch B treatment on serum Apo B48 and VLDL levels}

Serum Apo B48 and VLDL, which are involved in TG transport and formation, respectively, were examined in Sch B-treated mice. As shown in Fig. 2a, Sch B treatment significantly increased serum Apo B48 levels by 7 , $11,12,12,10$, and $10 \%$ at 12, 24, 48, 72, 96 and $120 \mathrm{~h}$ post dosing $(P<0.01)$, respectively, when compared with the control group. Sch B also markedly elevated serum Apo B48 levels by $8-11 \%$ in a dose-dependent manner $(P<0.01)$, with $E_{\max }(3926.8 \mathrm{ng} / \mathrm{mL}), K_{\mathrm{D}}(0.22 \mathrm{mmol} / \mathrm{kg})$ and $\mathrm{p} D_{2}$ (3.66) being estimated (Fig. 2b). Sch B markedly decreased serum VLDL levels by $19 \%$ at $24 \quad(P<0.05)$ and $48(P<0.01) \mathrm{h}$ post treatment (Fig. 2c). Furthermore, Sch B $(0.25$ and $0.5 \mathrm{~g} / \mathrm{kg})$ significantly decreased serum VLDL levels by $20(P<0.01)$ and $15 \%(P<0.05)$, respectively, at $24 \mathrm{~h}$ post treatment, but no detectable changes were observed after dosing with Sch B at 1 and $2 \mathrm{~g} / \mathrm{kg}$, when compared with the control group (Fig. 2d).

\section{Effects of Sch B treatment on serum NEFA and HGF levels}

NEFA is mainly released from adipose tissue by lipolysis. Figure 3a shows that Sch B (1 g/kg) significantly elevated serum NEFA levels by $55,37,34$, and $32 \%$ at $24,48,72$, and $96 \mathrm{~h}$ post dosing, respectively. Furthermore, Sch B dose-dependently increased serum NEFA levels by approximately $59 \%$ at $24 \mathrm{~h}$ post-treatment $(P<0.01)$, with values of $E_{\max }, K_{\mathrm{D}}$ and $\mathrm{p} D_{2}$ being estimated to be $545.4 \mu \mathrm{mol} / \mathrm{L}, 1.80 \mathrm{mmol} / \mathrm{kg}$, and 2.74 , respectively (Fig. 3b). HGF, a polypeptide implicated in liver regeneration, was examined in Sch B-treated mice. Serum HGF levels were increased by $71,54,54$, and $42 \%(P<0.05$ or $P<0.01)$ at $24,48,72$ and 96 h post treatment with Sch $\mathrm{B}$, respectively (Fig. 3c). Sch B dose-dependently increased serum HGF levels by $24-86 \%$ at 24 h post treatment $(p<0.01)$, with the values for $E_{\max }, K_{\mathrm{D}}$, and $\mathrm{p} D_{2}$ being estimated to be $219.95 \mathrm{mmol} / \mathrm{L}, 3.51 \mathrm{mmol} / \mathrm{kg}$, and 2.45 , respectively (Fig. $3 \mathrm{~d}$ ).

\section{Adipose tissue}

\section{Effects of Sch B treatment on EAT and adipocyte mass}

Figure 4 shows that Sch B treatment reduced the EAT mass in a time-/dose-dependent manner. Sch B $(1 \mathrm{~g} / \mathrm{kg})$ decreased the EAT index by $22,24,39$, and $32 \%$ at 12 , 24, 48 and $72 \mathrm{~h}$ post dosing, respectively (Fig. 4a). The maximal effect of Sch B-induced degradation of EAT was observed at $48 \mathrm{~h}$ post treatment. In addition, Sch B ( 1 and $2 \mathrm{~g} / \mathrm{kg}$ ) significantly decreased the EAT index by 24 and $30 \%$, respectively, at $24 \mathrm{~h}$ post-treatment, with 

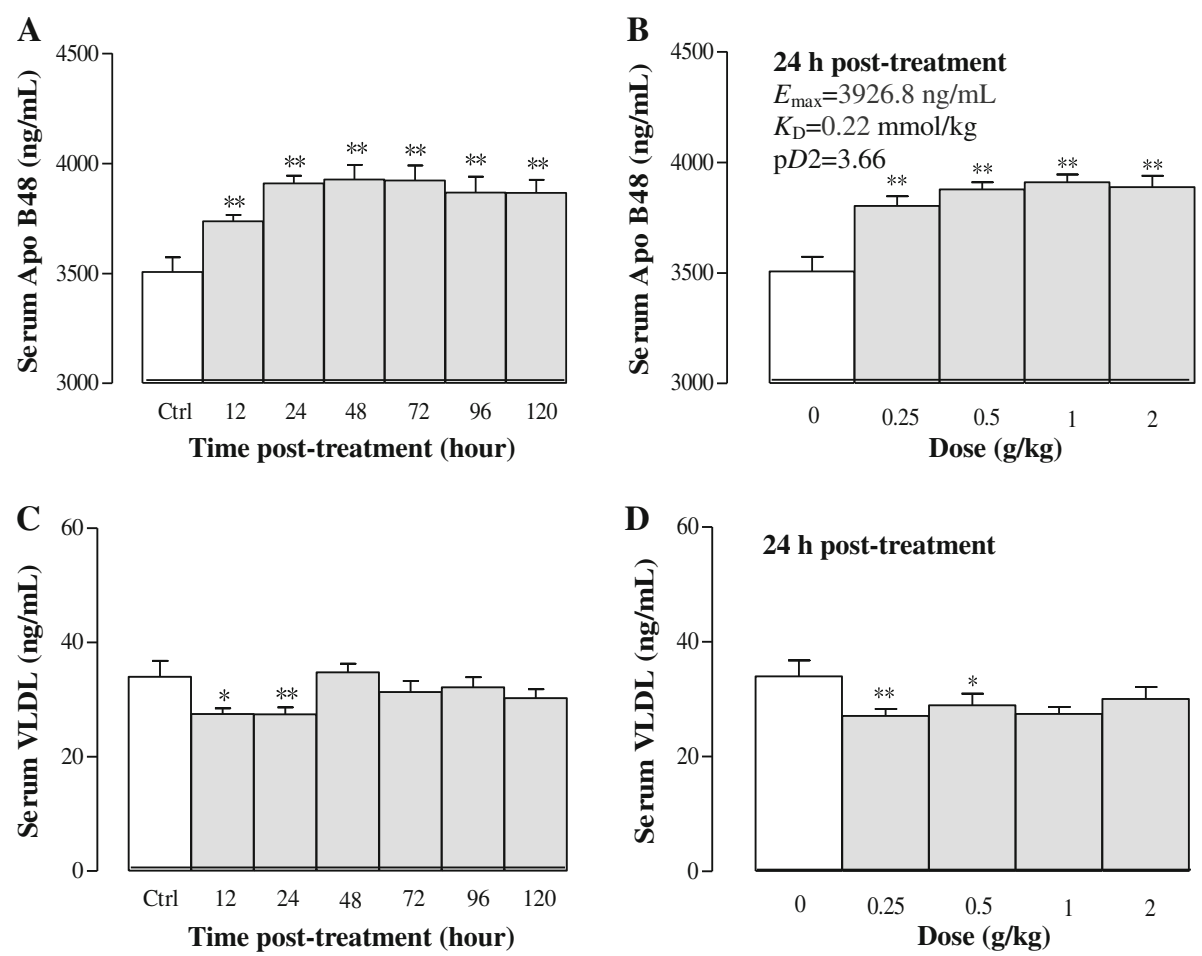

Fig. 2 Time/dose response of Sch B treatment on serum apolipoprotein B48 (Apo B48) and very-low-density lipoprotein (VLDL) levels. Experimental details were described in Fig. 1. For the time course study, serum Apo 48 and VLDL levels were measured at 12, 24, 48, 72, 96, and 120 h after Sch B treatment (a and $\mathbf{c}$ ). For the dose-response study, mice were intragastrically treated with Sch B $(0.25-2 \mathrm{~g} / \mathrm{kg})$. Twenty-four h later, serum samples were obtained to determine the Apo B 48 and VLDL levels, as well as the $E_{\max } K_{D_{1}}$ and $p D_{2}$ values $(\mathbf{b}$ and $\mathbf{d})$. Values given are the mean $\pm S E M$, with $n=10$. ${ }^{*} P<0.05,{ }^{*} P<0.01$ vs Control, using a one-way ANOVA followed by Dunnett's multiple comparisons test, Student's $t$-test or post-hoc analysis

values of $E_{\max }(0.47 \mathrm{mmol} / \mathrm{kg}), K_{\mathrm{D}}(2.15 \mathrm{mmol} / \mathrm{kg})$ and $\mathrm{p} D_{2}$ (2.67) being estimated (Fig. 4b). Histological examination of EAT section indicated that Sch B at $1 \mathrm{~g} / \mathrm{kg}$ decreased the adipocyte size in a time-dependent manner. As shown in Fig. 4c and d, the equivalent area of adipocytes was significantly lowered by $43,47,67,52,16$, and $12 \%$ at $12,24,48,72,96$ and 120 h post-dosing with Sch B $(1 \mathrm{~g} / \mathrm{kg})$, respectively $(P<0.01)$. The maximal effect of Sch $B$ on the reduction of adipocyte mass was observed at $48 \mathrm{~h}$ post treatment. Additionally, a restoration of normal adipocyte morphology was observed at $120 \mathrm{~h}$ after Sch B treatment $(1 \mathrm{~g} / \mathrm{kg})$.

\section{Liver}

\section{Effects of Sch B treatment on hepatic TG and TC contents}

Figure $5 \mathrm{a}$ and $\mathrm{b}$ show that Sch $\mathrm{B}$ increased hepatic TG contents in a time-/dose-dependent manner. Sch B $(1 \mathrm{~g} / \mathrm{kg})$ increased hepatic TG by $76,114,158,112$, and $40 \%$ at 12,24 , 48,72 , and 96 h post treatment, respectively. Sch B dosedependently increased hepatic TG contents by $71-111 \%$ at $24 \mathrm{~h}$ post-treatment, with values of $E_{\max }(23.64 \mu \mathrm{mol} / \mathrm{g}$ liver tissue), $K_{\mathrm{D}}(1.95 \mathrm{mmol} / \mathrm{kg})$ and $\mathrm{p} D_{2}(2.71)$ being estimated. Sch B increased hepatic TC contents by $26-53 \%(P<0.01)$ from 48 to $120 \mathrm{~h}$ post treatment. However, Sch B reduced hepatic TC contents by $34 \%$ at $24 \mathrm{~h}$ post-treatment (Fig. $5 \mathrm{c}$ ).
As Sch B treatment produced a biphasic effect on hepatic TC levels, the values of $E_{\max }, K_{\mathrm{D}}$, and $\mathrm{p} D_{2}$ were estimated at 24 and $48 \mathrm{~h}$ post dosing. Sch B $(0.25-2 \mathrm{~g} / \mathrm{kg})$ decreased hepatic TC levels by $16-38 \%(P<0.01)$ at 24 h post dosing, with values of $E_{\max }\left(1.82 \mu \mathrm{mol} / \mathrm{g}\right.$ liver tissue), $K_{\mathrm{D}}$ $(0.69 \mathrm{mmol} / \mathrm{kg})$ and $\mathrm{p} D_{2}$ (3.16) being estimated (Fig. $5 \mathrm{~d}$ ). Hepatic TC content was elevated by $10-33 \%$ at $48 \mathrm{~h}$ post treatment, with values of $E_{\max }, K_{\mathrm{D}}$ and $\mathrm{p} D_{2}$ being estimated to be $6.37 \mu \mathrm{mol} / \mathrm{g}$ liver tissue, $0.19 \mathrm{mmol} / \mathrm{kg}$, and 3.72 , respectively (Fig. 5e).

\section{Effects of Sch B treatment on hepatic lipid accumulation}

To confirm the effect of Sch B on lipid accumulation in the liver, Oil red $\mathrm{O}$ staining was performed to distinguish and quantify the accrual of lipid deposits (LD) in liver tissues. Administration with Sch B at $1 \mathrm{~g} / \mathrm{kg}$ induced an accumulation of lipids in liver tissue, as evidenced by the detection of an average of $10.4-, 17.5-, 12.5-, 4.8-, 1.6 \times 10^{3} \mu^{2}$ of lipid positive staining area at $12,24,48,72$ and $96 \mathrm{~h}$ post dosing, respectively (Fig. 6a and b). The maximum lipid accumulation occurred at $24 \mathrm{~h}$ post treatment, which was manifested as numerous large cytosolic lipid droplets around the central vein. Furthermore, hepatic steatosis was fully recovered at $120 \mathrm{~h}$ post dosing 

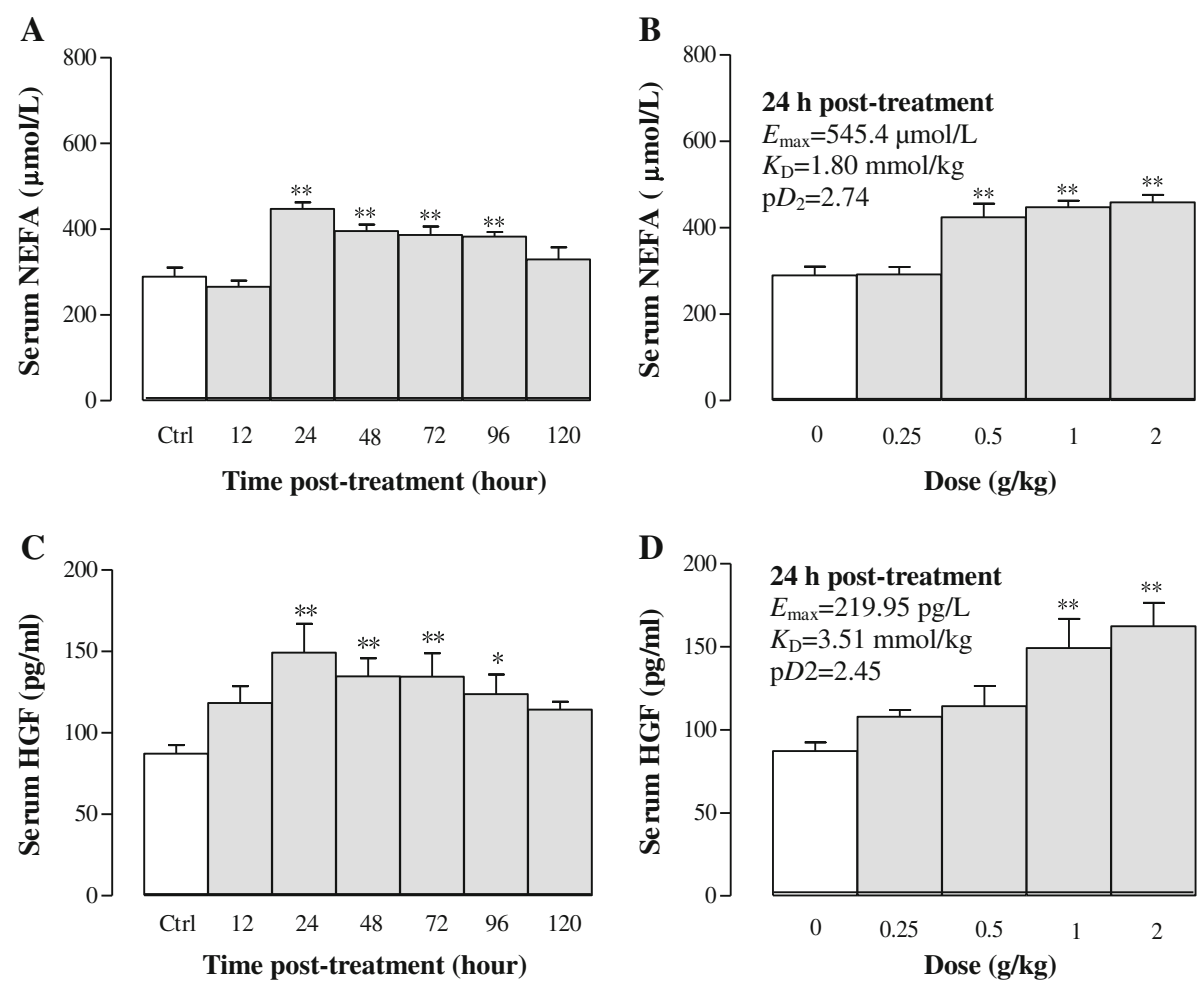

Fig. 3 Time/dose response of Sch B treatment on serum non-esterified fatty acid (NEFA) and hepatocyte growth factor (HGF) levels. Experimental details were described in Fig. 1. For the time course study, serum NEFA and HGF levels were measured at 12, 24, 48, 72, 96 and 120 after Sch B treatment (a and c). For the dose-response study, mice were intragastrically treated with Sch B $(0.25-2 \mathrm{~g} / \mathrm{kg})$. Twenty-four $24 \mathrm{~h}$ later, the pharmacodynamic parameters $\left(E_{\text {max }}\right.$ $K_{\mathrm{D}}$, and $\mathrm{p} \mathrm{D}_{2}$ ) were estimated ( $\mathbf{b}$ and $\mathbf{d}$ ). Values given are the mean $\pm \mathrm{SEM}$, with $\mathrm{n}=10 .{ }^{*} P<0.05$, ${ }^{* *} P<0.01$ vs Control, using a one-way ANOVA followed by Dunnett's multiple comparisons test, Student's t-test or post-hoc analysis

with Sch B at $1 \mathrm{~g} / \mathrm{kg}$. In addition, Sch B $(0.25-2 \mathrm{~g} / \mathrm{kg})$ treatment caused hepatic steatosis, as indicated by dose-dependent increases in lipid positive staining area $\left(2.6 \times 10^{3}-31.2 \times 10^{3} \mu \mathrm{m}^{2}\right)$ (Fig. $7 \mathrm{a}$ and b).

\section{Effects of Sch B treatment on hepatic mass and hepatocyte structure}

Figure 8 shows that Sch B treatment enhanced hepatic weight in a time-/dose-dependent manner. Sch $B$ increased hepatic index by $18-60 \%$ at $12-120 \mathrm{~h}$ post treatment. The maximum effect of Sch B treatment on hepatic index was observed at $48 \mathrm{~h}$ post dosing (Fig. 8a). Sch B $(0.25-2 \quad \mathrm{~g} / \mathrm{kg})$ dosedependently increased hepatic index by $24-29 \%$ at $24 \mathrm{~h}$ post treatment, with values of $E_{\max }(7.58), K_{\mathrm{D}}$ $(0.15 \mathrm{mmol} / \mathrm{kg})$ and $\mathrm{p} D_{2}(3.82)$ being estimated (Fig. 8b). The liver tissue was stained with $\mathrm{HE}$ and observed under an optical microscope $(\times 200)$. It was found that the structure of hepatic lobules was intact in the control group, as characterized by the radiating arrangement of hepatic cells and cords around the central vein, as well as clear and uniform Disse's spaces. In addition, hepatocytes were relatively large in size and polygonic in shape, with rich cytoplasm and large nuclei in the center without detectable steatosis. However, Sch B treatment $(1 \mathrm{~g} / \mathrm{kg})$ increased hepatic lipid deposits, which appeared as small vacuoles within the cytoplasm of liver cells at $12 \mathrm{~h}$ post treatment. Moreover, large numbers and different sizes of circular vacuoles were observed in the cytoplasm at $24 \mathrm{~h}$ post dosing with Sch B, featuring macrovesicular steatosis and hepatocyte ballooning. The extent of hepatic steatosis was gradually ameliorated from $48 \mathrm{~h}$ post treatment onwards, with the complete recovery observable at $120 \mathrm{~h}$ post treatment (Fig. 8c and d). Sch B treatment $(0.25-2 \mathrm{~g} / \mathrm{kg})$ dose-dependently increased the total vacuole area in liver tissue by $169-380 \%$ (Fig. 9a and $\mathrm{b})$.

\section{Effects of Sch B treatment on hepatocyte ultrastructure}

Electron microscopic analysis indicated that Sch B treatment $(1 \mathrm{~g} / \mathrm{kg})$ induced ultrastructural abnormalities in hepatic mitochondria, which was in association with hepatic steatosis. In the control group, there were numerous mitochondria of different shapes and sizes in the cytoplasm, and their cristae were well defined and arranged closely to one another. However, sparse 
A

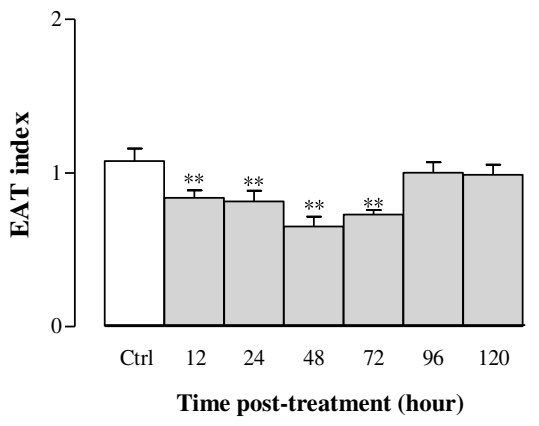

B

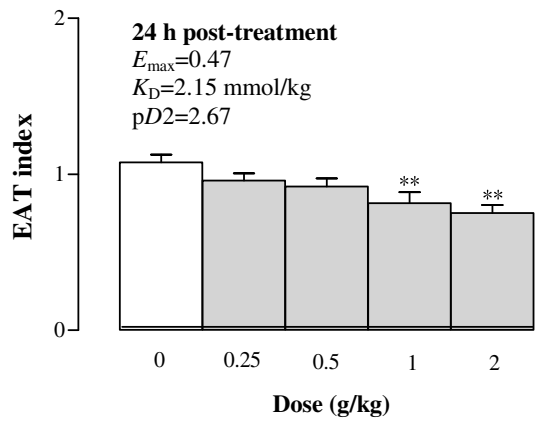

C
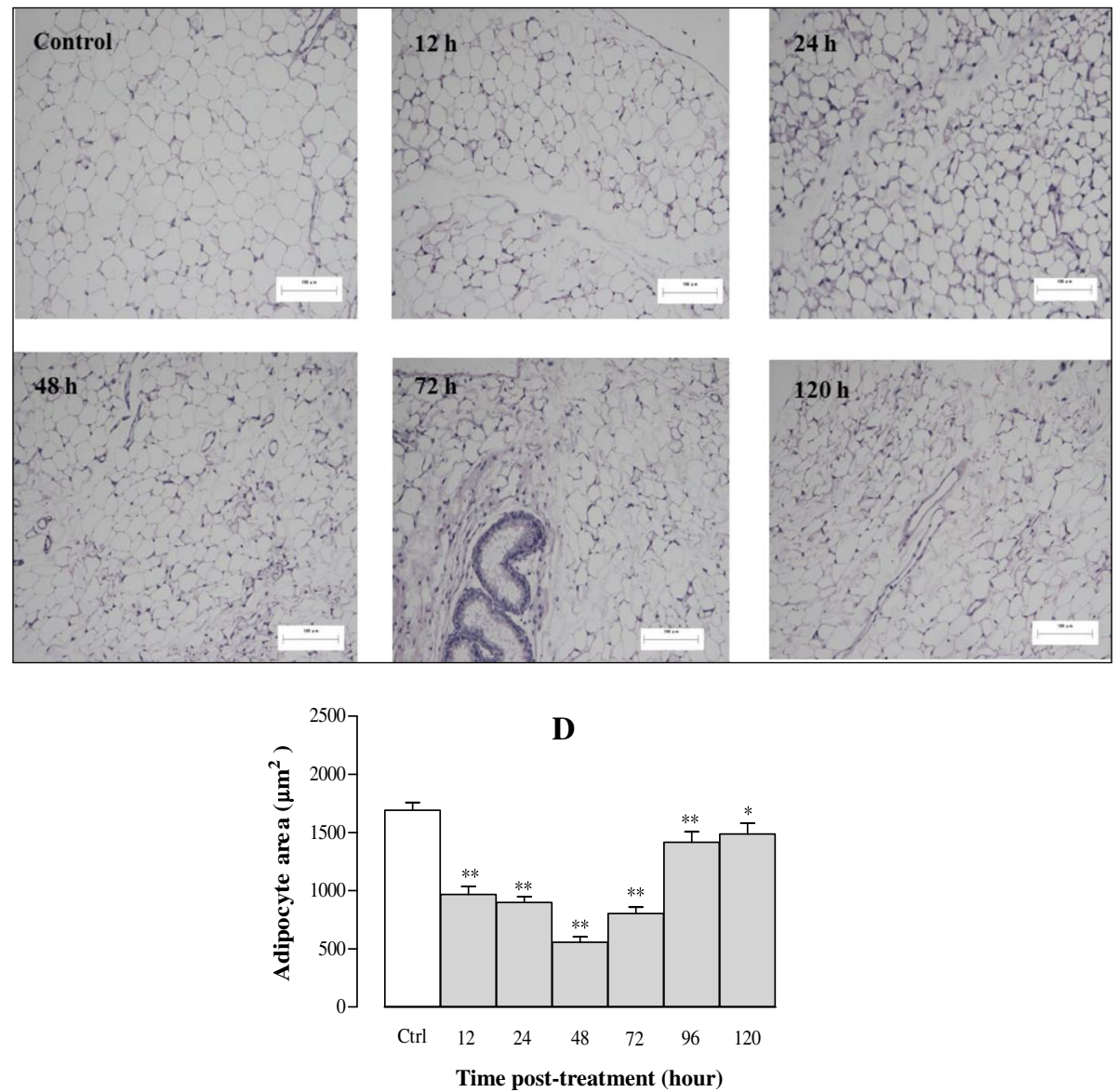

Fig. 4 Time/dose response of Sch B treatment on epididymal adipose tissue (EAT) and adipocyte mass. Experimental details were described in Fig. 1. For the time course study, EAT index (EAT weight/body weight $\times 100$ ) and adipocyte size were measured at 12, 24, 48, 72, 96, and 120 h after Sch B treatment ( $\mathbf{a}, \mathbf{b}$ and $\mathbf{d})$. A representative microscopic picture of a haematoxylin and eosin (HE)-stained EAT section for each group is shown in (c). The adipocyte area of each section was computed by Image Proplus 6.0. For the dose-response study, mice were intragastrically treated with Sch B (0.25-2 g/kg). Twenty-four h later, the pharmacodynamic parameters ( $E_{\max }, K_{\mathrm{D}}$ and $\left.\mathrm{p} D_{2}\right)$ of $\mathrm{Sch} B$ on EAT index were measured $(\mathbf{b})$. Values given are the mean $\pm \mathrm{SEM}$, with $n=10 .{ }^{*} P<0.05,{ }^{*} P<0.01$ vs Control, using a one-way ANOVA followed by Dunnett's multiple comparisons test, Student's $t$-test or post-hoc analysis

mitochondria which appeared swollen with disrupted cristae, together with clear and abundant lipid droplets in hepatocytes were observed at $72 \mathrm{~h}$ post-treatment with Sch B. Morphological damage of mitochondria was found to be recovered at $120 \mathrm{~h}$ post-dosing (Fig. 10).

\section{Discussion}

The synthesis of TG in humans mainly involves exogenous and endogenous pathways. The exogenous pathway starts with the intestinal absorption of TG from dietary sources in the form CM [23]. In the endogenous 

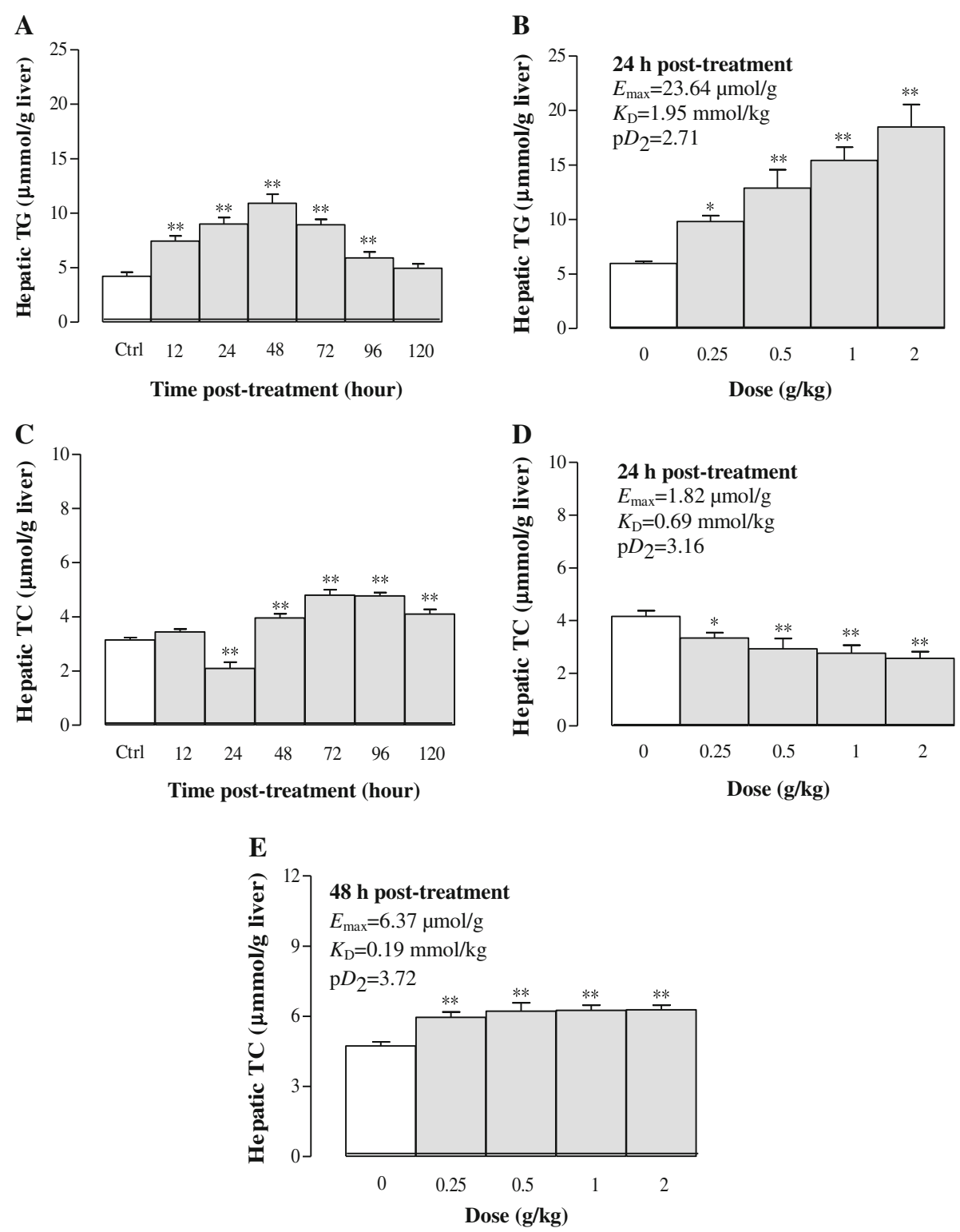

Fig. 5 Time/dose response of Sch B treatment on hepatic triglyceride $(T G)$ and total cholesterol (TC) contents. Experimental details were described in Fig. 1. For the time course study, hepatic TG and TC contents were measured at $12,24,48,72,96$, and $120 \mathrm{~h}$ after Sch B treatment (a and $\mathbf{c}$ ). For the dose-response study, mice were intragastrically treated with Sch B $(0.25-2 \mathrm{~g} / \mathrm{kg})$. Twenty-four $\mathrm{h}$ and forty-eight $\mathrm{h}$ later, the pharmacodynamic parameters $E_{\max }, K_{\mathrm{D}}$ and $\mathrm{pD}_{2}$ were determined (b, $\mathbf{d}$ and $\mathbf{e}$ ). Values given are the mean $\pm \mathrm{SEM}$, with $n=10 .{ }^{*} P<0.05,{ }^{*} P<0.01$ vs Control, using a one-way ANOVA followed by Dunnett's multiple comparisons test, Student's t-test or post-hoc analysis

pathway, TG is synthesized using fatty acids in the liver and it is carried by TG-rich VLDL into bloodstream [24]. Therefore, TG in the blood mainly exists in the form of CM and/or VLDL. In the present study, Sch B treatment increased serum TG levels in a time-/dosedependent manner from 6 to $96 \mathrm{~h}$ post-dosing. However, the serum TC level was elevated between 24 and $48 \mathrm{~h}$ after Sch B treatment. Scott's plot analysis showed that the potency of Sch B-induced elevation in serum TG is about 15.8-fold higher than that of TC. Moreover, no significant changes were detected in serum HDL and
LDL levels at all time points following the administration of Sch B (data not shown). High blood TG levels in both animals and humans result from either the suppression of TG catabolic pathway or promotion of TG synthetic pathway, or both. Results obtained from the present study suggest that Sch B-induced hypertriglyceridemia mainly involves exogenous pathway, as indicated by a high level of serum Apo B 48 (a unique marker of intestine-derived CM [25]) after Sch B treatment. The present study adopted a high, single oral dose of Sch B (compared with relatively long-term, lower 


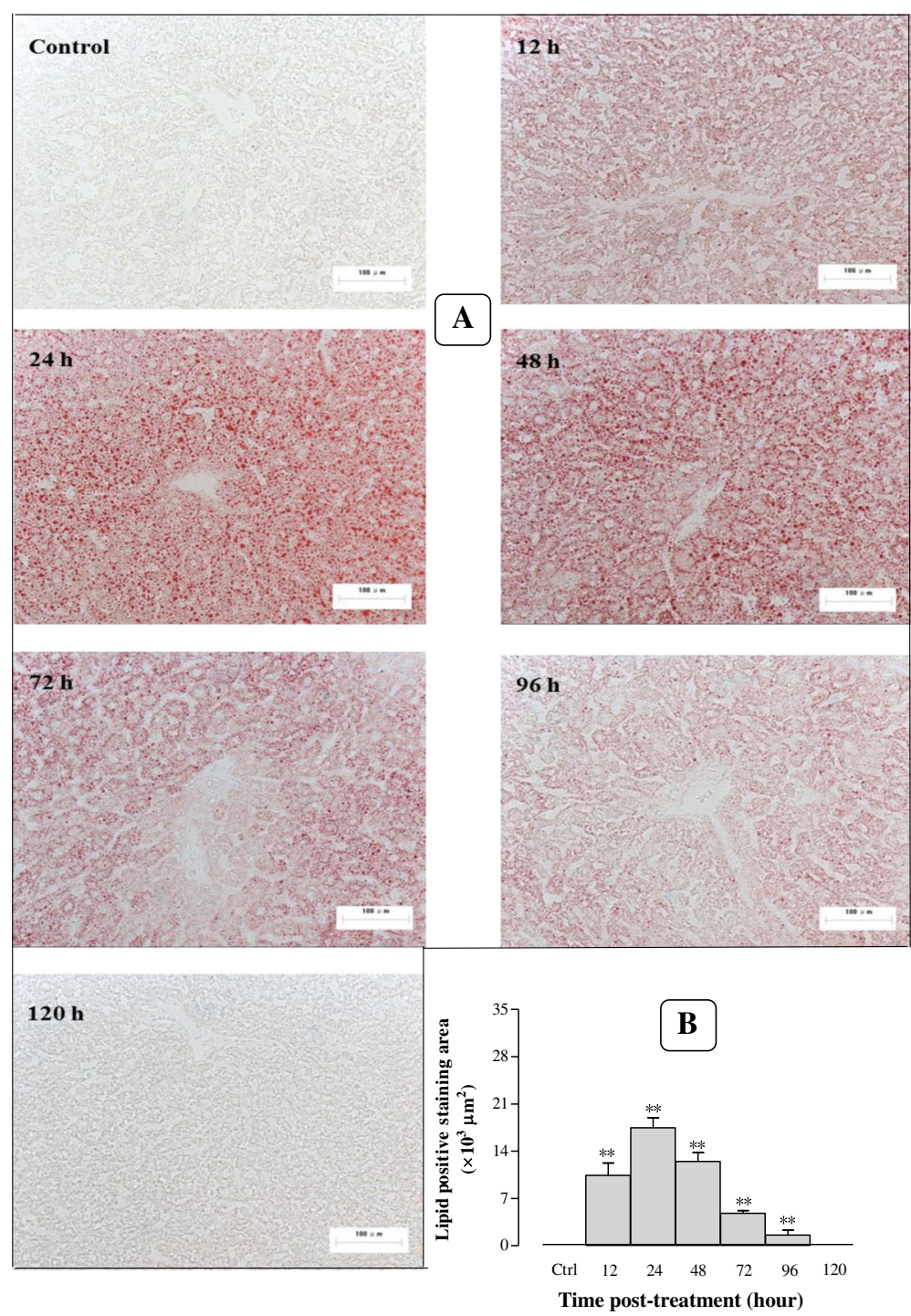

Fig. 6 Time response of Sch B treatment on hepatic steatosis. Experimental details were described in Fig. 1. Mice were orally administered with Sch B (1 g/kg). Control (untreated) animals received the vehicle only. After 12, 24, 48, 72, 96, and $120 \mathrm{~h}$, mice were sacrificed, and livers were removed and frozen by liquid nitrogen. A representative microscopic picture of Oil Red O-stained liver tissue section for each group is shown in $\mathbf{a}$, lipid positive staining area of each section was computed by Image Proplus 6.0 (b). Values given are the mean \pm SEM, with $n=10$. ${ }^{*} P<0.05$, ${ }^{*} P<0.01$ vs Control, using a one-way ANOVA followed by Dunnett's multiple comparisons test, Student's $t$-test or post-hoc analysis

doses used in other pharmacological studies in rodents) in order to induce changes in lipid metabolism in vivo. Presumably, the high dose of Sch B can elicit biological responses in various tissues in a time-dependent manner via specific signaling pathways.

Adipose tissue, an anatomical description for loose connective tissue composed of adipocytes, also plays an important role in lipid metabolism [26]. Adipocyte dysfunction may result in dysregulation of a wide range of adipose tissue-derived secretory factors, referred to as adipokines, which promote the release of NEFAs from adipocytes into the blood stream. The NEFAs are then delivered to the liver for TG synthesis [27]. In the present study, Sch B treatment time-/dose-dependently increased lipolysis, as evidenced by decreases in EAT and adipocyte size. Moreover, serum NEFA level was elevated after Sch B treatment, which may provide substrates for endogenous TG synthesis. The same $\mathrm{p} D_{2}$ values between serum NEFA and adiposity index suggest that the NEFA-elevating and adipose-degradating actions of Sch B are mediated by the same enzyme (s) and/or receptor (s).

TG is the main form of lipids in liver tissue. Therefore, hypertriglyceridemia, which is associated with an excess accumulation of NEFA and cholesterol in liver tissue, may result in hepatic steatosis, also named NAFLD and 


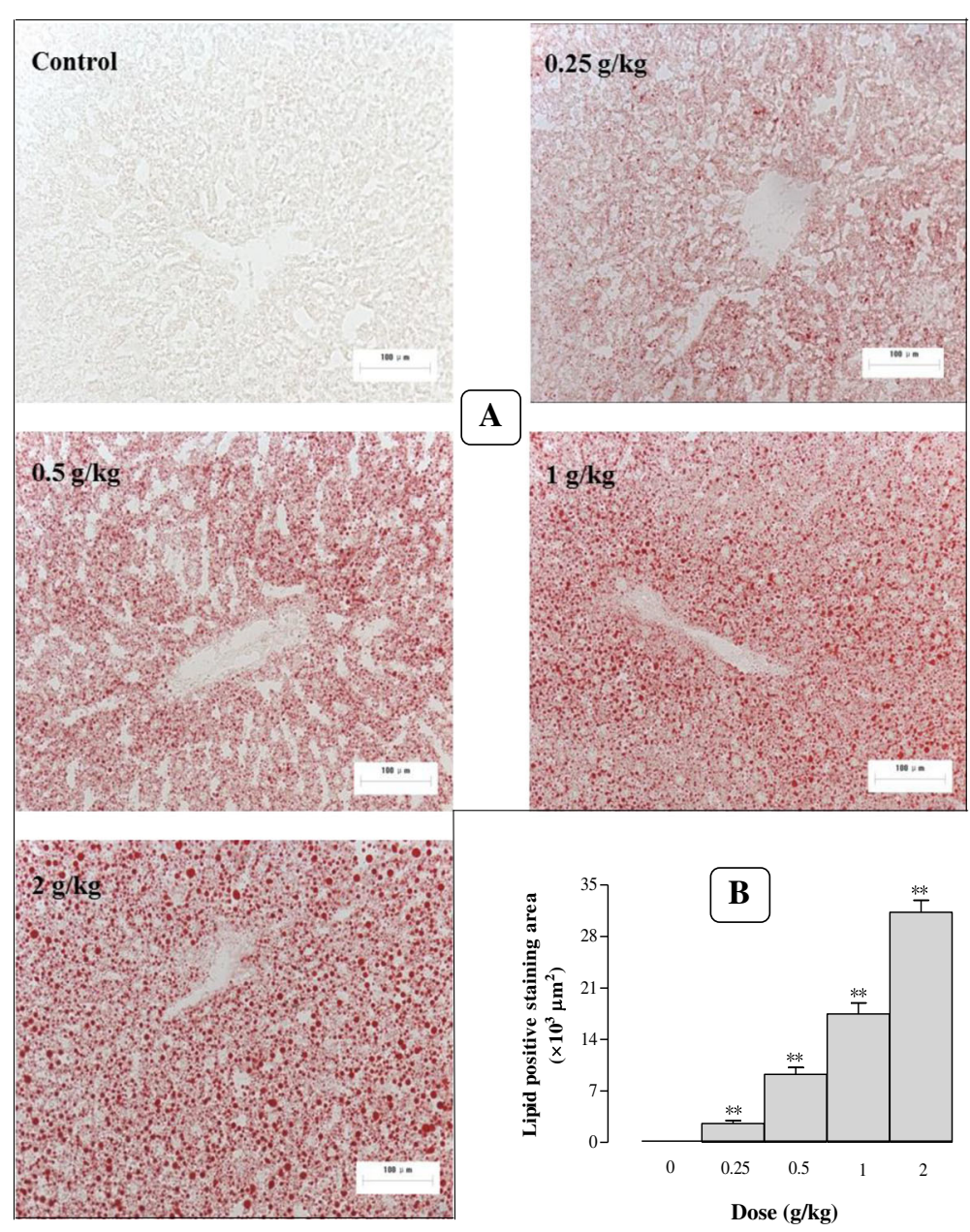

Fig. 7 Dose response of Sch B treatment on hepatic steatosis. Experimental details were described in Figs. 1 and 6. Mice were intragastrically treated with Sch B (0.25-2 g/kg) or vehicle. Twenty-four h later, a representative microscopic picture of Oil Red O-stained liver tissue section is shown in (a). The lipid positive staining area of each section was computed by Image Proplus 6.0 (b). Values given are the mean \pm SEM, with $n=10$. ${ }^{*} P<0.05,{ }^{* *} P<$ 0.01 vs Control, using a one-way ANOVA followed by Dunnett's multiple comparisons test, Student's t-test or post-hoc analysis

nonalcoholic steatohepatitis with or without fibrosis and hepatocellular carcinoma [28]. In other words, NAFLD features the entire alcohol-like spectrum of liver disease though it is observed in the nonalcoholic, dysmetabolic individual free of competing causes of liver disease [29]. Moreover, NEFA exhibits intrahepatic TG storage, giving rise to lipotoxicity, which it has now become a major public issue [30]. In the present study, a single dose of Sch B increased serum TG level (approximately 424\%) which was accompanied with hepatomegaly, hepatic steatosis and hepatic mitochondrial injury (i.e., hepatotoxicity). Our previous study showed that fenofibrate, a widely prescribed TG-lowering agent, could eliminate Sch B- and Sch oil-induced hypertriglyceridemia, hepatic steatosis, and liver injury [20,31]. It has been demonstrated that Sch B caused hepatotoxicity (increase in serum ALT activity [19] via PI3K/AKt/mtOR signaling pathway in our previous study [32]. We consider that
Sch B-induced hypertriglyceridemia and hepatic steatosis resulted from the lipolysis (decrease in adipocyte size and increase in serum NEFA) and exogenous sources (increase in serum Apo B48). Sch B-induced hepatomegaly resulted from fat accumulation and mitochondrial damage in liver tissue. Therefore, the mouse model of Sch B-induced hypertriglyceridemia/NAFLD (such as nonalcoholic steatohepatitis), which manifests hypertriglyceridemia secondary to hepatic steatosis/steatohepatitis, is useful for investigating TG metabolism and developing lipid-lowering drug. The mouse model requires less time to be established, when compared with those done by high fat diet and genetic ablation [33, 34]. As for the pathway (s) involved in Sch B-induced hypertriglyceridemia, hepatic steatosis, and lipolysis remain to be studied further.

HGF, a multifunctional growth factor, is the most potent mitogen for hepatocyte proliferation [35]. It has 

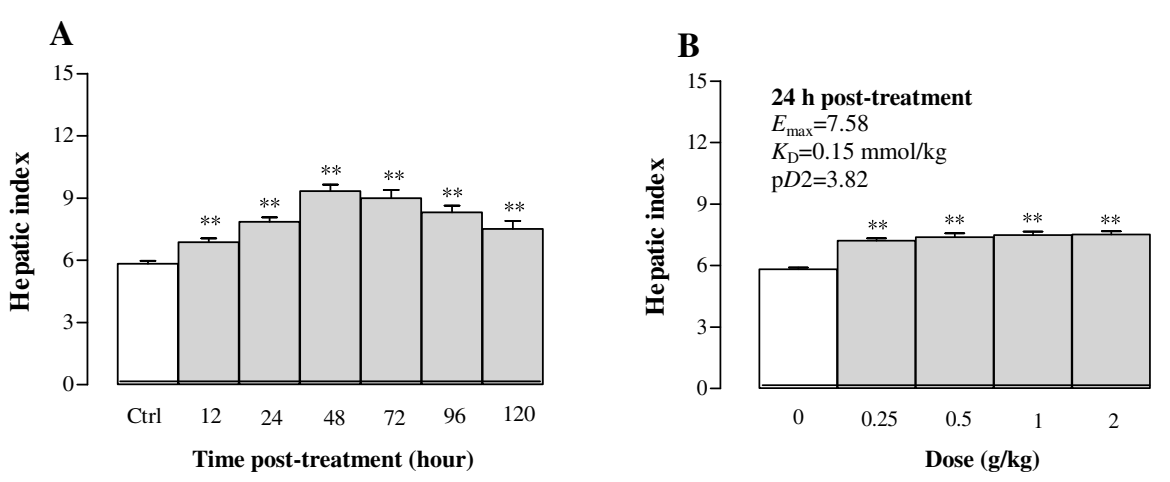

C
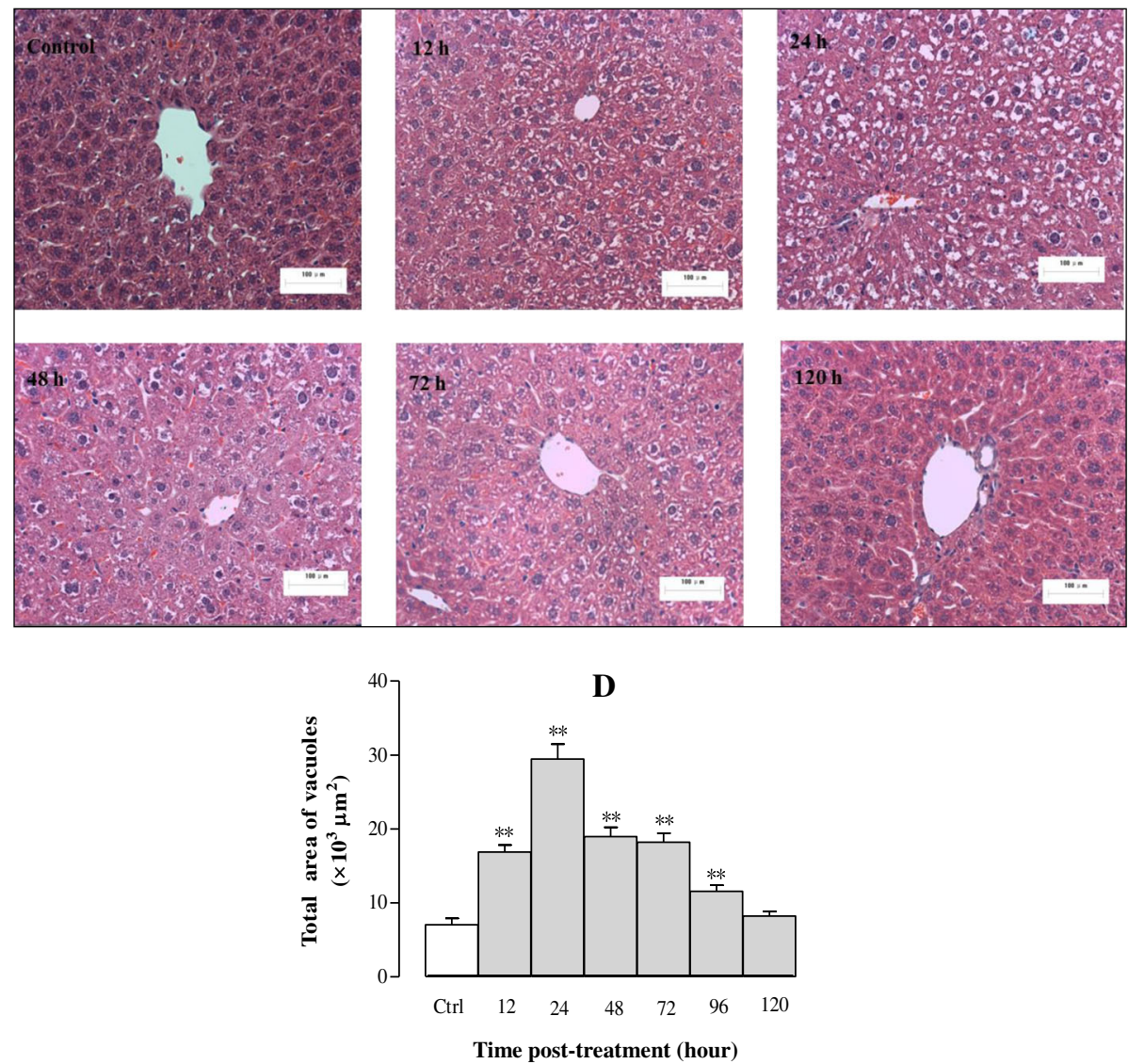

Fig. 8 Time/dose response of Sch B treatment on hepatic mass and haematoxylin and eosin (HE) stain. Experimental details were described in Fig. 1. At $24 \mathrm{~h}$ after Sch B treatment, mice were sacrificed, and livers were removed and weighed to calculate the hepatic index (hepatic weight/body weight $\times$ $100)$ and pharmacodynamic parameters $\left(E_{\text {max }} K_{\mathrm{D}_{1}}\right.$ and $\left.\mathrm{pD}_{2}\right)$ shown in $(\mathbf{a}$ and $\mathbf{b})$. Then liver samples were fixed in $10 \%$ formalin and stained with $\mathrm{HE}$. A representative microscopic picture of a HE-stained liver tissue section for each group is shown in $\mathbf{c}$, and total vacuole area of each section was computed by Image Proplus 6.0 (d). Values given are the mean \pm SEM, with $n=10 .{ }^{*} P<0.05,{ }^{* *} P<0.01$ vs Control, using a one-way ANOVA follow by Dunnett's multiple comparisons test, Student's t-test or post-hoc analysis

been reported that HGF regulates lipid metabolism and thus ameliorates a high-fat diet-induced fatty liver through stimulating lipid secretion [36]. In the present study, it was found that the time periods for the onset/ peak/recovery of Sch B-induced elevation in serum TG levels, serum HGF levels, hepatic TG contents and hepatic mass were found to be $12 / 24 / 96,24 / 24 / 120,12 / 48$ /
120 , and $12 / 48 />120 \mathrm{~h}$ post dosing, respectively. The temporal relationships among these parameters suggest that hepatic steatosis and hepatomegaly secondary to the Sch B-induced increase in serum TG level may be causally related to an increase in HGF release and/or production. In addition, the huge difference existing between $\mathrm{p} D_{2}$ of HGF and $\mathrm{p} D_{2}$ of hepatomegaly further 


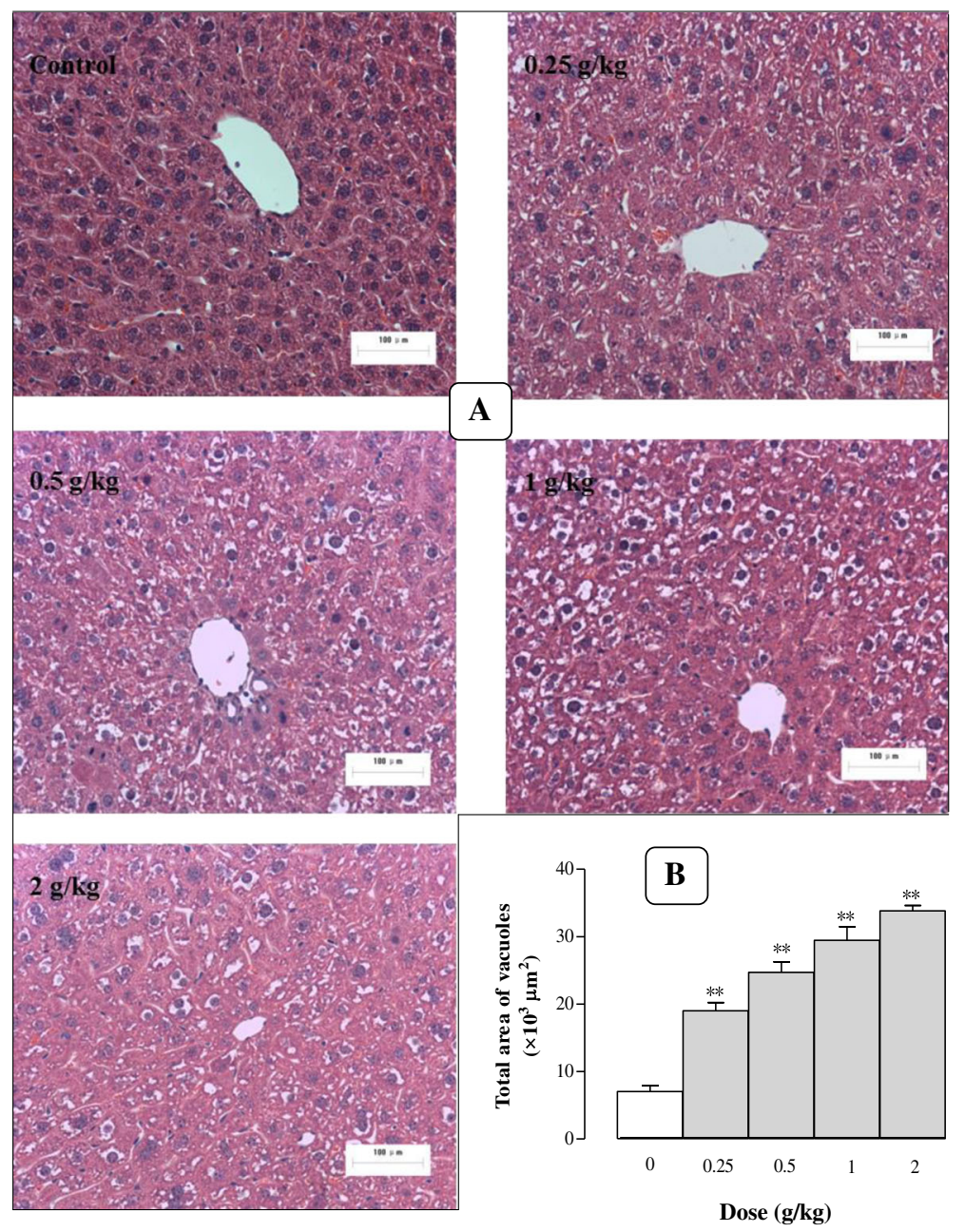

Fig. 9 Dose response of Sch B treatment on hepatocyte structure. Experimental details were described in Fig. 1 and 8. Mice were intragastrically treated with Sch B $(0.25-2 \mathrm{~g} / \mathrm{kg})$ or vehicle. At $24 \mathrm{~h}$ after Sch B treatment, liver tissue sections were stained with HE (a). The total vacuole area of each section was computed by Image Proplus 6.0 (b). Values given are the mean \pm SEM, with $n=10 .{ }^{*} P<0.05$, ${ }^{* *} P<0.01$ vs Control, using a one-way ANOVA followed by Dunnett's multiple comparisons test, Student's $t$-test or post-hoc analysis

suggests that the Sch B-induced elevation in serum HGF level and hepatic mass may be mediated by different enzyme (s) and/or receptor (s).

Hepatic steatosis accelerates the progression of liver injury via activation of stellate cells and pro-apoptotic factors [37]. It also triggers the release of proinflammatory cytokines, such as interleukin $1 \beta$ and tumor necrosis factor- $\alpha$ from hepatocytes, which promote the progression of hepatic steatosis to non-alcohol steatohepatitis, fibrosis, and even cirrhosis [38]. In the present study, histopathological examination revealed that Sch B treatment caused the development of hepatic macrovesicular steatosis, which was evidenced by the presence of single and large fat droplets that push the nucleus to the periphery of the hepatocyte. Moreover, microvesicular steatosis, which is characterized by the presence of small vesicles filling the cytoplasm of hepatocytes, also occurred. Our previous study has shown that serum ALT activity (an enzyme marker of liver damage) was elevated in association with hepatic steatosis [17], suggesting that hepatic lipid accumulation may cause liver injury. However, there was no detectable infiltration of inflammatory cells in the liver during the observed time course of post-Sch B treatment. These observations might be explained in part by the apoptotic effect produced by Sch B on Kupffer cells [32], which play crucial roles in mediating the inflammatory processes that promote liver injury [39]. Therefore, Sch Binduced hepatic steatosis produces liver damage without eliciting an inflammatory response.

Changes in the structure of hepatocyte mitochondria were observed following the Sch B treatment. Mitochondria are the organelles primarily involved in lipid oxidation and ATP production by utilizing intermediates 


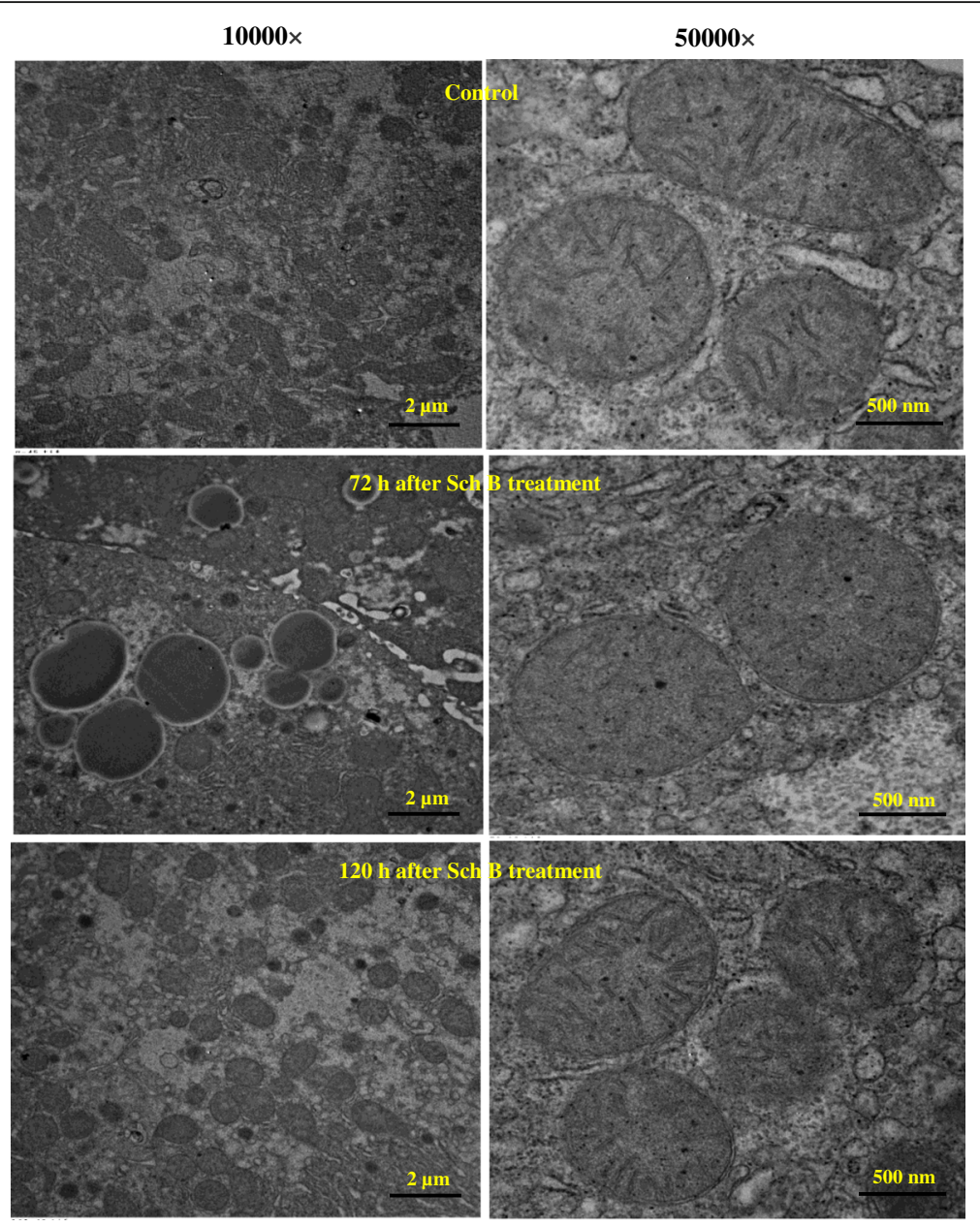

Fig. 10 Time response of Sch B treatment on hepatocyte ultrastructure. Experimental details were described in Fig. 1. Mice were orally administered with Sch B (1 g/kg). Control (untreated) animals received the vehicle only. After 72 and $120 \mathrm{~h}$, mice were sacrificed and liver tissues were removed and fixed in $2 \%$ glutaraldehyde Sorensen's phosphate buffer. Then ultrathin sections were made and stained with uranyl acetate and lead citrate for TEM

derived from fatty acid and glucose metabolism. Accumulating evidence has shown that hepatic mitochondrial dysfunction is crucially involved in the pathogenesis of NAFLD in which disturbances on lipid oxidation and mitochondrial DNA integrity can induce lipid steatosis and trigger apoptotic pathway, respectively [15, 40]. Hepatic mitochondria exhibited morphological disruption following the Sch B treatment, wherein mitochondrial sizes were slightly increased and cristae were disrupted, indicative of mitochondrial structural and functional abnormalities that may subsequently promote the accumulation of lipid vacuoles in the cytoplasm of hepatocytes.

\section{Conclusions}

In conclusion, the results obtained from the present study indicated that Sch B treatment time-/dose-dependently elevated serum and hepatic TG levels, which were associated with increase in serum Apo B48, but not VLDL, level. In addition, Sch B treatment markedly reduced EAT and adipocyte size as well as increased serum NEFA level in a time/dose-dependent manner. At the same time, changes such as hepatomegaly, high serum HGF level and hepatic steatosis were also observed in Sch B-treated mice. Histopathological analysis indicated that Sch B time-/dose-dependently promoted hepatic steatosis, which may be related to mitochondrial dysfunction in Sch B-treated mice. The ensemble of results suggests that a mouse model of hypertriglyceridemia associated hepatic steatosis and hepatotoxicity can be established by applying a single oral dose of Sch B. The animal model is useful for investigating lipid metabolism and discovering novel lipid-lowering agents.

\section{Abbreviations}

Apo B48: Apolipoprotein B48; CM: Intestinal chylomicron; EAT: Epididymal adipose tissue; FFA: Free fatty acid; HGF: Hepatocyte growth factor;

MTTP: Microsomal triglyceride transfer protein; NEFA: Non-esterified fatty acid; Sch B: schisandrin B; TC: Total cholesterol; TEM: Trasmission electron microscopy; TG: Triglyceride; VLDL: Very low density lipoprotein 


\section{Acknowledgements}

Not applicable.

\section{Funding}

This work was supported by a grant from the National Natural Science Foundation of China (Grant No 31071989) and Self-Topic Fund of Beijing University of Chinese Medicine (2014-JYBZZ-XS-104).

\section{Availability of data and material}

All data sets generated and analysed during this study are available from the corresponding authors upon email request.

\section{Authors' contributions}

Design of the study: SYP, MX; conduct of the study: YZ, JZ, XYW, PLZ, ZSC; data collection: YZ, JZ; data analysis: YZ, SYP, ZLY; data interpretation: SYP, SFZ, KMK; manuscript writing: YZ, JZ, SYP. All authors read and approved the final manuscript.

\section{Competing interests}

The authors declare that they have no competing interests.

\section{Consent for publication}

Not applicable.

\section{Ethics approval and consent to participate}

Use of animals in the current study was approved by the University Committee on Research Practice in Beijing University of Chinese Medicine.

\section{Author details}

'Department of Pharmacology, Beijing University of Chinese Medicine, Beijing 100102, China. ${ }^{2}$ Institute of Integrated Bioinfomedicine \& Translational Science, HKBU Shenzhen Research and Continuing Education, Shenzhen 518057, China. ${ }^{3}$ Department of Bioengineering and Biotechnology, College of Chemical Engineering, Huaqiao University, Xiamen, Fujian 361021, China. ${ }^{4}$ School of Chinese Medicine, Hong Kong Baptist University, Hong Kong, SAR, China. ${ }^{5}$ Department of Formulaology, Beijing University of Chinese Medicine, Beijing 100029, China. ${ }^{6}$ Division of Life Science, Hong Kong University of Science \& Technology, Hong Kong, SAR, China.

\section{Received: 4 December 2016 Accepted: 2 January 2017}

\section{Published online: 13 January 2017}

\section{References}

1. Cameron AJ, Shaw JE, Zimmet PZ. The metabolic syndrome: prevalence in worldwide populations. Endocrinol Metab Clin North Am. 2004;33:351-75.

2. Carpentier AC. Hypertriglyceridemia associated with abdominal obesity: getting contributing factors into perspective. Arterioscler Thromb Vasc Biol. 2015;35:2076-8.

3. Watts GF, Karpe F. Republished review: Triglycerides and atherogenic dyslipidaemia: extending treatment beyond statins in the high-risk cardiovascular patient. Postgrad Med J. 2011;87:776-82.

4. Subramanian S, Chait A. Hypertriglyceridemia secondary to obesity and diabetes. Biochim Biophys Acta. 2012;1821:819-25.

5. Charlesworth A, Steger A, Crook MA. Acute pancreatitis associated with severe hypertriglyceridaemia; A retrospective cohort study. Int I Surg. 2015;25:23-7.

6. Sangwan A, Tewari S, Singh H, Sharma RK, Narula SC. Periodontal status and hyperlipidemia: statin users versus non-users. J Periodontol. 2013;84:3-12.

7. Hsu JH, Chien IC, Lin CH, Chou YJ, Chou P. Hyperlipidemia in patients with schizophrenia: national population-based study. Gen Hosp Psychiatry. 2012; 34:360-7.

8. Farrell GC, Larter CZ. Nonalcoholic fatty liver disease: from steatosis to cirrhosis. Hepatology. 2006;1:S99-S112.

9. Loria P, Marchesini G, Nascimbeni F, Ballestri S, Maurantonio M, Carubbi F, et al. Cardiovascular risk, lipidemic phenotype and steatosis. A comparative analysis of cirrhotic and non-cirrhotic liver disease due to varying etiology. Atherosclerosis. 2014;232:99-109.

10. Hassing HC, Surendran RP, Mooij HL, Stroes ES, Nieuwdorp M, Dallinga-Thie GM. Pathophysiology of hypertriglyceridemia. Biochim Biophys Acta. 2012; 21:826-32.

11. Checker R, Patwardhan RS, Sharma D, Menon J, Thoh M, Bhilwade HN, et al. Schisandrin B exhibits anti-inflammatory activity through modulation of the redox-sensitive transcription factors Nrf2 and NF-KB. Free Radic Biol Med. 2012:53:1421-30.

12. Zeng KW, Zhang T, Fu H, Liu GX, Wang XM. Schisandrin B exerts antineuroinflammatory activity by inhibiting the Toll-like receptor 4-dependent MyD88/IKK/NF-KB signaling pathway in lipopolysaccharide-induced microglia. Eur J Pharmacol. 2012;692:29-37.

13. Li L, Pan Q, Han W, Liu Z, Li L, Hu X. Schisandrin B prevents doxorubicininduced cardiotoxicity via enhancing glutathione redox cycling. Clin Cancer Res. 2007;13:6753-60.

14. Chiu PY, Leung HY, Siu AH, Poon MK, Ko KM. Schisandrin B decreases the sensitivity of mitochondria to calcium ion-induced permeability transition and protects against ischemia-reperfusion injury in rat hearts. Acta Pharmacol Sin. 2007:28:1559-65.

15. Ip SP, Poon MK, Wu SS, Che CT, Ng KH, Kong YC, et al. Effect of schisandrin $B$ on hepatic glutathione antioxidant system in mice: protection against carbon tetrachloridetoxicity. Planta Med. 1995;61:398-401.

16. Ip SP, Che CT, Kong YC, Ko KM. Effects of schisandrin B pretreatment on tumor necrosis factor-a induced apoptosis and Hsp 70 expression in mouse liver. Cell Stress Chaperones. 2001:6:44-8.

17. Li L, Lu Q, Shen Y, Hu X. Schisandrin B enhances doxorubicin-induced apoptosis of cancer cells but not normal cells. Biochem Pharmacol. 2006;71:584-95.

18. Xu Y, Liu Z, Sun J, Pan Q, Sun F, Yan Z, et al. Schisandrin B prevents doxorubicin-induced chronic cardiotoxicity and enhances its anticancer activity in vivo. PLoS One. 2011;6:e28335.

19. Zhang Y, Pan SY, Zhou SF, Wang XY, Sun N, Zhu PL, et al. Time and dose relationships between schisandrin B- and Schisandrae fructus oil-induced hepatotoxicity and the associated elevations in hepatic and serum triglyceride levels in mice. Drug Des Devel Ther. 2014;8:1429-39.

20. Pan SY, Jia ZH, Zhang Y, Yu Q, Wang XY, Sun N, et al. Novel mouse model of combined hyperlipidemia associated with steatosis and liver injury by a single-dose intragastric administration of schisandrin B/cholesterol/bile salts mixture. J Pharmacol Sci. 2013;123:110-9.

21. Pan SY, Dong H, Han YF, Li WY, Zhao XY, Ko KM. A novel experimental model of acute hypertriglyceridemia induced by schisandrin B. Eur J Pharmacol. 2006; 537:200-4.

22. Lambert JE, Parks EJ. Postprandial metabolism of meal triglyceride in humans. Biochim Biophys Acta. 2012;1821:721-6.

23. Reiner Z, Koren E. Triglyceride-poor very low density lipoprotein in human serum. Clin Chim Acta. 1979;94:23-9.

24. Kinoshita M, Kojima M, Matsushima T, Teramoto T. Determination of apolipoprotein B-48 in serum by a sandwich ELISA. Clin Chim Acta. 2005; 351:115-20.

25. Bernlohr DA, Simpson MA. Adipose tissue and lipid metabolism. New Comprehensive Biochemistry. 1996;31:257-381.

26. Jung UJ, Choi MS. Obesity and its metabolic complications: the role of adipokines and the relationship between obesity, inflammation, insulin resistance, dyslipidemia and nonalcoholic fatty liver disease. Int J Mol Sci. 2014;15:6184-223.

27. McClain CJ, Barve S, Deaciuc I. Good fat/bad fat. Hepatology. 2007;45:1343-6.

28. Ballestri S, Nascimbeni F, Romagnoli D, Baldelli E, Lonardo A. The Role ofNuclear Receptors in the Pathophysiology, Natural Course, and Drug Treatment of NAFLD in Humans. Adv Ther. 2016;33:291-319.

29. Lonardo A, Bellentani S, Argo CK, Ballestri S, Byrne CD, Caldwell SH, et al. Epidemiological modifiers of non-alcoholic fatty liver disease: Focus on high-risk groups. Dig Liver Dis. 2015;47:997-1006.

30. Pan SY, Dong H, Guo BF, Zhang Y, Yu ZL, Fong WF, et al. Effective kinetics of schisandrin B on serum/hepatic triglyceride and total cholesterol levels in mice with and without the influence of fenofibrate. Naunyn Schmiedebergs Arch Pharmacol. 2011;383:585-91.

31. Trevaskis JL, Griffin PS, Wittmer C, Neuschwander-Tetri BA, Brunt EM, Dolman CS, et al. Glucagon-like peptide-1 receptor agonism improves metabolic, biochemical, and histopathological indices of nonalcoholic steatohepatitis in mice. Am J Physiol Gastrointest Liver Physiol. 2012; 302:G762-72.

32. Zhang Y, Zhou ZW, Jin H, Hu C, He ZX, Yu ZL, et al. Schisandrin B inhibits cell growth and induces cellular apoptosis and autophagy in mouse hepatocytes and macrophages: implications for its hepatotoxicity. Drug Des Devel Ther. 2015;9:2001-27.

33. Gu Q, Yang X, Lin L, Li S, Li Q, Zhong S, et al. Genetic ablation of solute carrier family 7a3a leads to hepatic steatosis in zebrafish during fasting. Hepatology. 2014;60:1929-41. 
34. Strain AJ, Ismail T, Tsubouchi H, Arakaki N, Hishida T, Kitamura N, et al Native and recombinant human hepatocyte growth factors are highly potent promoters of DNA synthesis in both human and rat hepatocytes. J Clin Invest. 1991:87:1853-7.

35. Kosone T, Takagi H, Horiguchi N, Ariyama Y, Otsuka T, Sohara N, et al. HGF ameliorates a high fat diet-induced fatty liver. Am J Physiol Gastrointest Liver Physiol. 2007;293:G204-10.

36. Walsh MJ, Vanags DM, Clouston AD, Richardson MM, Purdie DM, Jonsson JR, et al. Steatosis and liver cell apoptosis in chronic hepatitis C: a mechanism for increased liver injury. Hepatology. 2004;39:1230-8.

37. Sun B, Karin M. Obesity, inflammation, and liver cancer. J Hepatology. 2012; 56:704-13.

38. Kolios G, Valatas V, Kouroumalis E. Role of Kupffer cells in the pathogenesis of liver disease. World J Gastroenterol. 2006;12:7413-20.

39. Caldwell SH, Chang CY, Nakamoto RK, Krugner-Higby L. Mitochondria in nonalcoholic fatty liver disease. Clin Liver Dis. 2004;8:595-617.

40. Wei Y, Rector RS, Thyfault JP, Ibdah JA. Nonalcoholic fatty liver disease and mitochondrial dysfunction. World J Gastroenterol. 2008;14:193-9.

Submit your next manuscript to BioMed Central and we will help you at every step:

- We accept pre-submission inquiries

- Our selector tool helps you to find the most relevant journal

- We provide round the clock customer support

- Convenient online submission

- Thorough peer review

- Inclusion in PubMed and all major indexing services

- Maximum visibility for your research

Submit your manuscript at www.biomedcentral.com/submit
Biomed Central 